\title{
THE EFFECT OF FIBER ORIENTATION AND STRESS RATIO ON THE CRACK GROWTH BEHAVIOR OF FIBER METAL LAMINATES (FMLs)
}

\author{
Anindito Purnowidodo ${ }^{1 *}$, Khairul Anam ${ }^{1}$, Djarot B. Darmadi ${ }^{1}$, Ari Wahjudi ${ }^{1}$ \\ ${ }^{1}$ Mechanical Engineering Department, University of Brawijaya, Jl. MT. Haryono 167, Malang \\ 65145, East Java, Indonesia.
}

(Received: October 2017 / Revised: March 2018 / Accepted: April 2018)

\begin{abstract}
The crack growth behavior of fiber metal laminates (FMLs) with fiber orientations of $90^{\circ} / 0^{\circ}$ and $45^{\circ} / 45^{\circ}$ to load direction was investigated with varying stress ratios of the cyclic constant load. The study shows that crack growth behavior depends on the conditions of the cyclic load and the orientation of the fiberglass orientation. A higher stress ratio of the cyclic constant load causes fatigue life to decrease, and is associated with stress concentration just in front of the crack tip. The stress concentration in the FMLs with $45^{\circ} / 45^{\circ}$ fiberglass orientation is higher than that of $90^{\circ} \%^{\circ}$, which means the fatigue life in the former is shorter. The bridging of the fiberepoxy composite takes place when the stress ratio of the constant cyclic load is lower than 0.4 , which also enhances fatigue life.
\end{abstract}

Keywords: Bridging; Crack growth; Cyclic loads; Stress concentration; Stress ratio

\section{INTRODUCTION}

Nowadays, lightweight materials are commonly used in certain structures such as airplanes and boats, but these structures require high strength materials in order to ensure their safety. The strength to weight ratio is a parameter used to determine whether a material meets the requirement of a light weight structure or not. It is known that composites have a good strength to weight ratio, and in general airplane structures are made from these (Jones, 1999; Barsom \& Rofle, 1999; Stephens et al., 2001; Callister Jr. \& Rethwisch, 2007; Jones et al., 2016). The strength and weight of a composite depend on the material composing it; in general, it is composed of two parts, the matrix and reinforcement (Jones, 1999; Callister Jr. \& Rethwisch, 2007; Jones et al., 2016). There are several categories of composites, one of which is the fiber metal laminate type, also known as FMLs. This composite is used as the skin of an airplane body because its strength to weight ratio is very good (Jones, 1999; Callister Jr. \& Rethwisch, 2007). FMLs are composed of at least two plies of different materials. To reduce weight, a metal ply is usually combined with a ply of a fiber based composite (Jones, 1999). Carbon or glass fiber is used as the reinforcement of the composite.

It is almost inevitable that structures are subjected to dynamic rather than static load, and most cases of component failure are associated with this type of load (Barsom \& Rofle, 1999; Stephens et al., 2001; Jones et al., 2016). Dynamic load is more of a danger to the components of a structure than static load, although the magnitude of dynamic load is much lower (Barsom \& Rofle, 1999; Stephens et al., 2001). Fatigue failure is a type of failure relating to dynamic load, which originates in a crack initiation in a component; the crack then grows to a critical

\footnotetext{
*Corresponding author's email: anindito@ub.ac.id, Tel. +62-341-587710, Fax. +62-341-551430

Permalink/DOI: https://doi.org/10.14716/ijtech.v9i5.853
} 
length. If the crack reaches this critical length, the component is no longer capable of carrying the load, so it will fail. To estimate the lifetime of components subjected to dynamic load, a method based on crack growth is often used; using this method, the lifetime of components can be estimated before cracks reach a critical length.

In practice, to estimate the lifetime of a component based on fatigue crack growth, the crack growth behavior must be understood, which is greatly affected by the dynamic load conditions and the type of materials (Bao \& McEvily, 1995; Sadananda et al., 1999; Purnowidodo et al., 2004; Purnowidodo et al., 2007; Purnowidodo et al., 2009; Purnowidodo et al., 2016). Crack growth caused by fatigue load may also take place in the components of structures made from composites. However, the fatigue crack growth behavior of composites is not as fully understood as that of metals (Khan et al., 2011; Jianyu et al., 2012; Huang et al., 2015). This is because composites are composed of several kinds of materials, leading to different crack growth behavior for different types of composite.

Besides composite type, the loading conditions also affect fatigue crack growth behavior. In previous studies (Khan et al., 2011; Huang et al., 2015), the crack growth of FML composites was investigated under variable loading conditions, in which the cyclic loads were returned to the constant cyclic loads existing before the overload, and the crack growth was investigated after application of the overload. The investigations show that crack growth behavior after the overload depended on the delamination occurring in front of the crack tip. In this study, because the variable cyclic loads relate not only to the overload, but also to other loading conditions such as variations associated with the magnitude of cyclic loads, the mean stress, or the stress ratio of the cyclic loads, the investigation of the crack growth of the FMLs was investigated with varying loading conditions. Moreover, FML strength is also influenced by the orientation of the fiber (Khan et al., 2011; Jianyu et al., 2012; Huang et al., 2015: Dadej et al., 2017). Hence, observation of the crack growth was also made on FMLs with different fiber orientations in each stress ratio.

\section{METHODS}

The FMLs composites were made in the laboratory using the hand lay-up method. The metal selected to form the composite was commercial pure aluminium with a thickness of $0.4 \mathrm{~mm}$. After being heat treated at $300^{\circ} \mathrm{C}$ for one hour, and then cooled in the furnace, the yield and tensile strength of the aluminium were 85 and $105 \mathrm{MPa}$ respectively, and the elongation was $3 \%$. Commercial epoxy adhesive was first used to wet the surface of the aluminium, followed by placement of one layer of the plain woven fiberglass on the surface of the adhesive. Next, the adhesive was deposited on the surface of the fiber, and then the aluminium placed on the top of the laminate. The type of glass was E-glass with a tensile strength of $2300 \mathrm{MPa}$. According to the manufacturer, the adhesive is suitable for bonding metal and glass. After making the laminate, the process was then continued to press it at $20 \mathrm{MPa}$ for 20 seconds in laboratory room-temperature conditions. Because the manufacturer of the epoxy adhesive recommends that the curing time is at least 90 minutes, and that maximum strength is achieved after at least 6 hours, the laminate composites were loaded for testing after 6 hours. The dimensions of the specimen and the laminate sequence of the composite are shown schematically in Figure 1. A double edge crack type was used in the study, so a sharp notch $2.5 \mathrm{~mm}$ in length and $0.2 \mathrm{~mm}$ in width atthe notch root was machined on each edge of the specimen. To establish the effect of the orientation of the plain woven fiberglass on the composite, the fiber orientation was arranged as $0^{\circ} / 90^{\circ}$ and $45^{\circ} / 45^{\circ}$ to the load direction. Figure 2 shows an example of the plain woven fiberglass used in the study. The yield and tensile strength of the FMLs were found to be high as 65 and $100 \mathrm{MPa}$, respectively with $1 \%$ maximum elongation. 


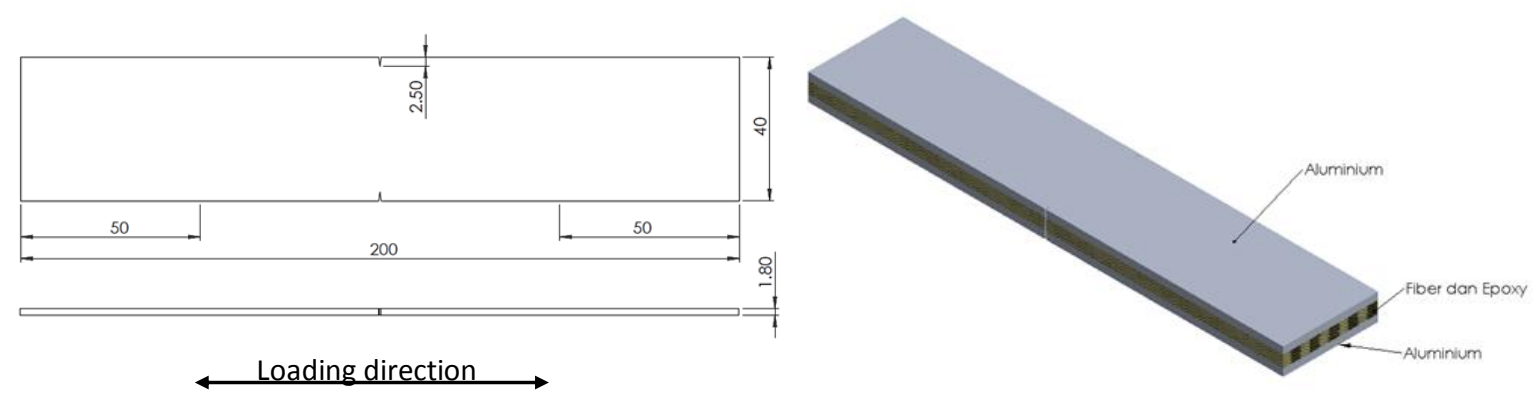

Figure 1 Dimensions of the FML composite specimen $(\mathrm{mm})$ and the laminate sequence

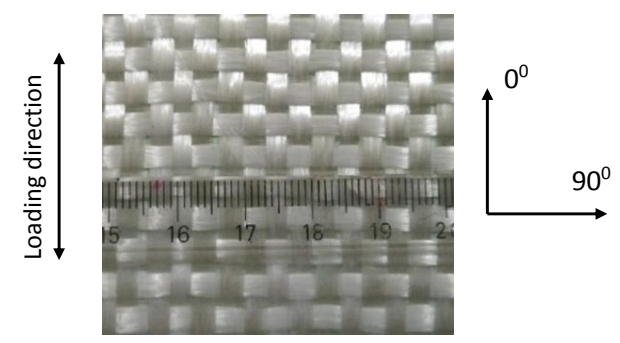

Figure 2 Plain woven fiberglass

Table 1 Testing conditions

\begin{tabular}{|c|c|c|c|c|c|}
\hline No & Material & $\begin{array}{c}S_{\max .} \\
\text { (Mpa.) }\end{array}$ & $R$ & $\begin{array}{c}S_{\text {amp. }} \\
\text { (Mpa.) }\end{array}$ & $\begin{array}{c}\text { Fiber } \\
\text { orientation }\end{array}$ \\
\hline 1 & \multirow{3}{*}{$\begin{array}{l}\text { Monolithic } \\
\text { Aluminium }\end{array}$} & 14 & 0 & \multirow{13}{*}{7} & \multirow{3}{*}{ 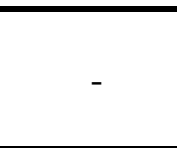 } \\
\hline 2 & & 17 & 0.2 & & \\
\hline 3 & & 21 & 0.3 & & \\
\hline 4 & \multirow{10}{*}{ FMLs Composite } & 14 & 0 & & \multirow{5}{*}{$0^{\circ} / 90^{\circ}$} \\
\hline 5 & & 17 & 0.2 & & \\
\hline 6 & & 21 & 0.3 & & \\
\hline 7 & & 24 & 0.4 & & \\
\hline 8 & & 28 & 0.5 & & \\
\hline 9 & & 14 & 0 & & \multirow{5}{*}{$45^{\circ} / 45^{\circ}$} \\
\hline 10 & & 17 & 0.2 & & \\
\hline 11 & & 21 & 0.3 & & \\
\hline 12 & & 24 & 0.4 & & \\
\hline 13 & & 28 & 0.5 & & \\
\hline
\end{tabular}

Table 1 shows the testing conditions. The stress ratio, $R$, is defined as the comparison between the minimum stress, $S_{\text {min }}$, and the maximum stress, $S_{\text {max. }}$, of the constant cyclic loads, and $S_{a m p}$. is the stress amplitude. The tests were conducted with a servo-hydraulic fatigue machine by cycling each specimen at a frequency of $4 \mathrm{~Hz}$ in laboratory-room temperature conditions. Figure 3 shows schematically an example of the pattern of the cyclic load condition when the stress ratio, $R$, is zero, with $S_{\text {mean. }}$ denoting the average of the constant cyclic loads. The semicrack length, $a$, is the average of the crack growing from both sides of the specimen, and it was measured including the notch length. A travelling digital microscope with an accuracy of $10 \mu \mathrm{m}$ was used to observe the crack growth. In order to make the crack growth on the surface of the aluminium laminate of the FMLs observable, the exterior surface of the laminate was polished with emery paper to obtain a mirror-like surface. 


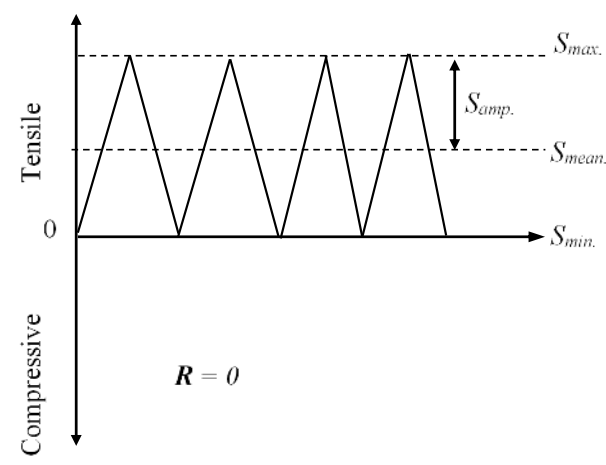

Figure 3 Example of a representative cyclic pattern

Because the crack growth on the FMLs is affected by the stress condition in front of the crack tip (Khan et al., 2011; Huang et al., 2015), this condition will cause delamination to occur in front of the tip. To calculate the stress distribution that concentrates locally in the tiny area just in front of the crack tip, a computer simulation was conducted with the aid of ABAQUS software based on the finite element method; the simulation was therefore based on the software code. For this purpose, and because of the symmetrical nature of the specimen, the specimen was modelled as a quarter model, and was meshed in the manner shown in Figure 4. The arrangement of the FML laminates is also shown in this figure. Because the advance of the crack is influenced by the maximum load of the constant cyclic loads, $S_{\max }$, analysis of the stress distribution in the region near the crack tip was made at the point of maximum load.

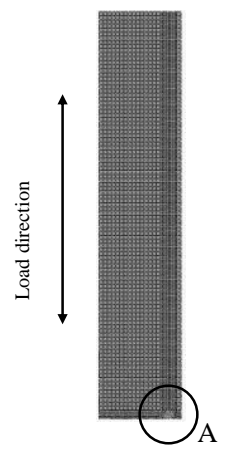

Quarter model

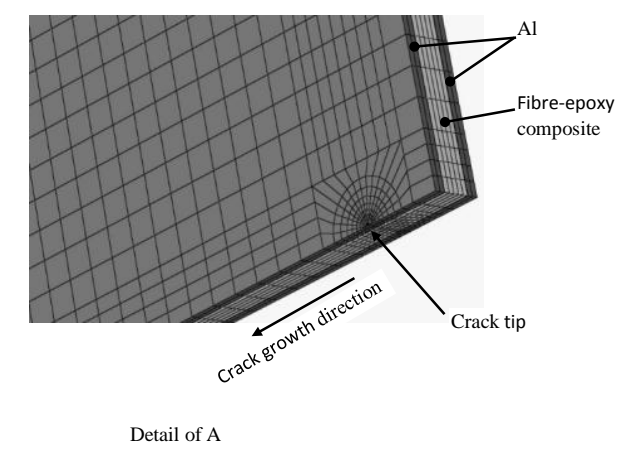

Figure 4 Meshing of the quarter 3D model

\section{RESULTS AND DISCUSSION}

The results of the crack growth behavior testing of the FMLs with various stress ratios, $R$, with the same magnitude of constant cyclic load, are shown in Figure 5, the left-hand side being the fiberglass orientation of $90^{\circ} / 0^{\circ}$ and the right-hand side that of $45^{\circ} / 45^{\circ}$. The lifetimes of each fiberglass orientation are compared to the fatigue life of the monolithic aluminium, which was decreased by increasing the stress ratio. Because the lifetime of the monolithic aluminium with a stress ratio of 0.3 was found to be very short, testing of the monolithic aluminium with a higher stress ratio was not carried out. The Figure 5 shows that the FMLs with $90 \% 0^{\circ}$ of fibreglass orientation have a longer lifetime than the monolithic aluminium for each stress ratio, and as the stress ratio is higher than 0.3, the lifetime of the FMLs is still longer than the monolithic aluminium with a stress ratio of 0.3 . The lifetime of the FMLs with fiber orientation equal to $45^{\circ} / 45^{\circ}$ is almost the same as the lifetime of the monolithic aluminium when the stress ratios are 0 and 0.2 , respectively. With the higher stress ratio than previous ones, the lifetime is 
shorter still, however these lifetimes are still much longer compared to the monolithic aluminium after being cycled with a stress ratio of 0.3 . In addition, the fatigue life of the fiberglass orientated at $90^{\circ} / 0^{\circ}$ is longer than that of $45^{\circ} / 45^{\circ}$ for each stress ratio. The results of the $R=0.5$ testing condition with fibreglass orientation of $45^{\circ} / 45^{\circ}$ does not plot in the figure, because the specimen broke immediately after being cycled, and the number of cycles of the specimen was very low.
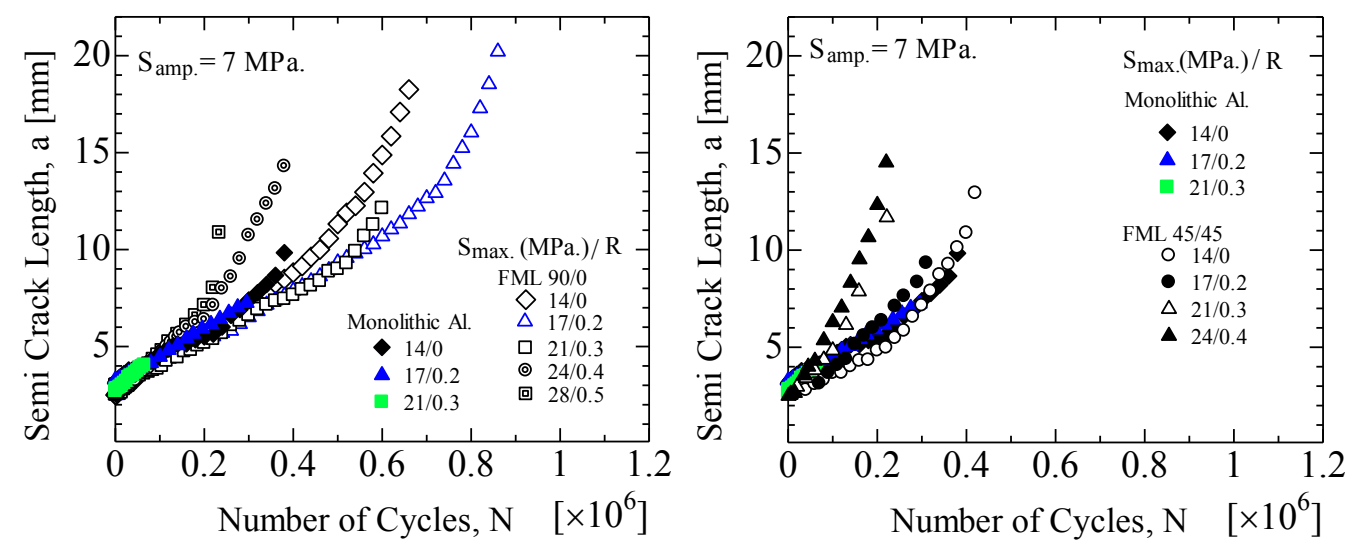

Figure 5 Semi crack length, a, vs. number of cycles, N

Figure 6 shows the relationship between the semi crack length, $a$, and the crack growth rate, $d a / d N$, demonstrating that the monolithic aluminium is vulnerable to the stress ratio, as indicated by the increase in the crack growth rate if the stress ratio is 0.3 , when the crack growth rate is higher than with other ratios, although the crack length is still short. The crack growth rate of the FMLs with fiberglass orientation of $90^{\circ} / 0^{\circ}$ cycled with stress ratios of 0.2 and 0.3 is almost the same as with the monolithic aluminium, but the crack length of the monolithic aluminium is shorter because it cannot suspend the stress concentration in the zone in front of the crack tip, which increases as the crack grows. The crack growth rate of the FMLs with $45^{\circ} / 45^{\circ}$ orientation almost coincides with the monolithic aluminium for each stress ratio when the stress ratios are 0.2 and 0.3 , however the FMLs is fail atlonger crack lengths. However, with stress ratios of 0.3 and 0.4 the crack growth rate of the FMLs with $45^{\circ} / 45^{\circ}$ orientation is higher than that of the monolithic aluminium, and the crack length at which failure occurs is still longer.
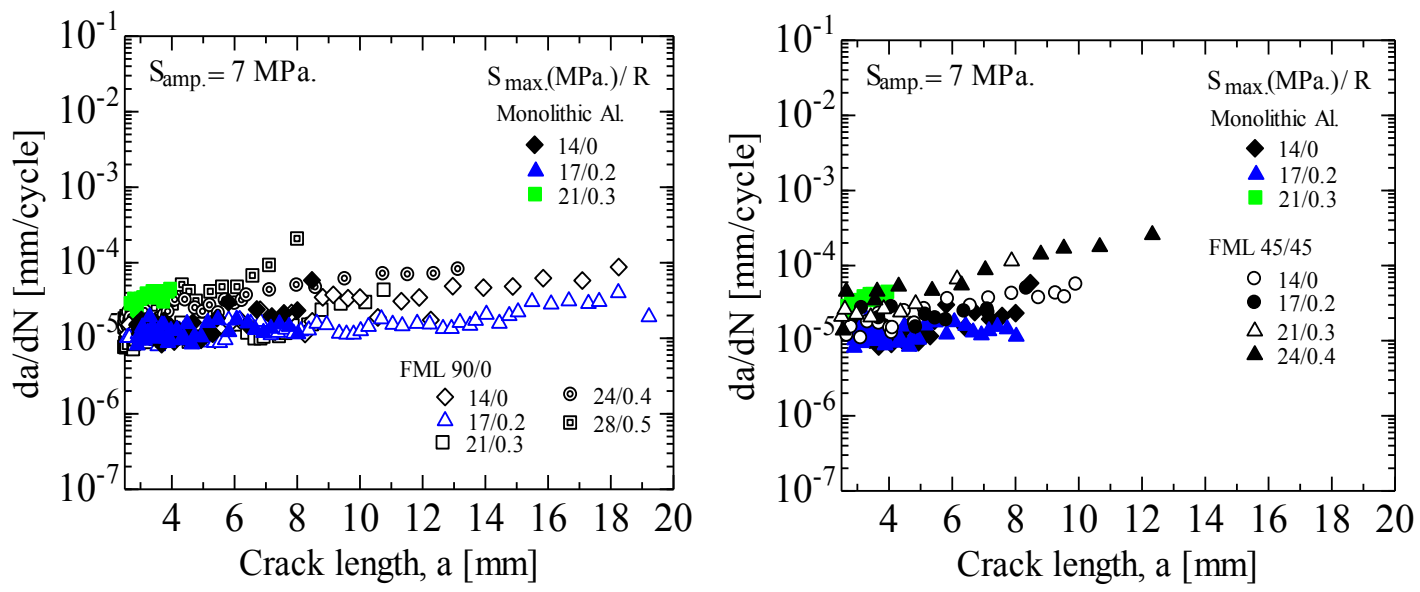

Figure 6 Semi crack length, a, vs. crack growth rate, da/dN 
The fatigue life for each material in the study is summarized in Figure 7, in which the solid and dashed lines represent the expectation line for the FMLs with fiberglass orientations of $90 \% 0^{\circ}$ and $45^{\circ} / 45^{\circ}$, respectively. The dash-dot line represents the expectation line for monolithic aluminium. It can be seen from the figure that in general increasing the stress ratio value reduces the lifetime of the materials, although they were cycled under constant cyclic loads with the same value of stress amplitude, $S_{a m p}$. In addition, the fatigue life of the FMLs with the $90^{\circ} / 0^{\circ}$ fiberglass orientation is higher than that of those with the $45^{\circ} / 45^{\circ}$ orientation. The arrangement of the fiberglass in the FMLs at the $45^{\circ} / 45^{\circ}$ orientation to the load direction slightly increases the fatigue life in comparison to the monolithic aluminium. The results of the study show that the fatigue life of the FMLs is greatly affected by the orientation of the fiberglass and the stress ratio.

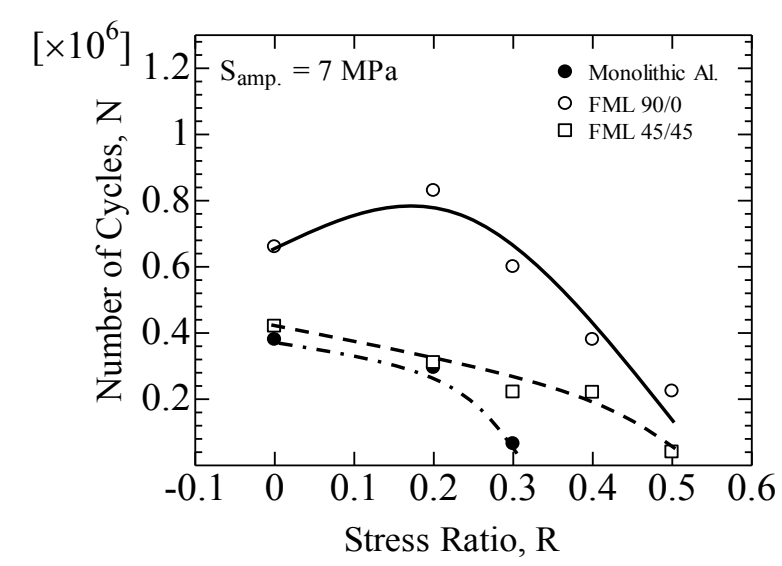

Figure 7 Effect of stress ratio on number of cycles

The crack growth caused by fatigue may determine the lifetime of a member. This lifetime associated with fatigue load can be divided into two types. First, the lifetime of a member can be dominated by crack initiation. In this case, the number of load cycles used to initiate a crack is larger than that used to grow the crack. Second, if the number of cycles used to grow the crack is larger than that used to initiate the crack, and it is called as the lifetime dominated by crack growth (Stephens et al., 2001). The type of domination of the lifetime does not only occur on metals, but may also occur in the composite, such as in this study. Figure 8 shows examples of FML failure conditions after being cycled with constant amplitude load with stress ratios of 0 and 0.5 , for FMLs with fiberglass orientation of $45^{\circ} / 45^{\circ}$. An example of stress ratio 0.4 with fibreglass orientation of $90^{\circ} / 0^{\circ}$ is also shown in the figure. In Figure $8 \mathrm{a}$, it can be seen that in the case of stress ratio 0 with fiberglass orientation $45^{\circ} / 45^{\circ}$, the failure caused by the fatigue load is longer than with the stress ratio of 0.5 , which means that the failure is dominated only by monotonic failure. This indicates that just after being cycled in the short period of the constant cyclic loads, the composite was not capable of carrying these loads. However, the existence of fatigue failure in front of the notch root can be seen in the Figure $8 \mathrm{c}$, when the stress ratio is as high as 0.4 , with fiberglass orientation of $90^{\circ} / 0^{\circ}$. The length of the fatigue failure on stress ratio 0.5 is shorter than that of 0.4 , which cannot be shown here because of the limited space. The length of fatigue failure indicates the strength of the FMLs to carry the cyclic loads. The Figure 8 shows that the length of this failure tends to be shorter in the FMLs with the fiberglass orientation of $45^{\circ} / 45^{\circ}$ than those with $90 \% 0^{\circ}$ orientation; this therefore leads to the fatigue life of the FMLs with the $90^{\circ} / 0^{\circ}$ fiberglass orientation being longer than that of the $45^{\circ} / 45^{\circ}$ orientation. In addition, bridging of the fiberglass was still observed after failure at the higher stress ratio, as shown in Figure 8c, for FMLs with the $90 \% 0^{\circ}$ fiberglass orientation. Instead of bridging, the fiberglass breaks, as shown in Figure $8 \mathrm{~b}$, when the orientation of the 
fibreglass is $45^{\circ} / 45^{\circ}$. Moreover, the increasing stress ratio reduces the domination of the fatigue failure type, and is associated with the bridging of the fibre, which tends to take place at the lower stress ratio.

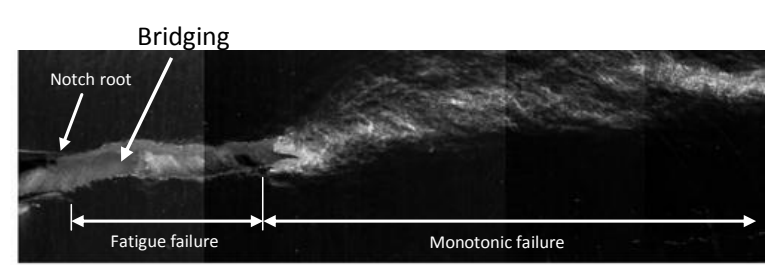

(a) $R=0,45 / 45$

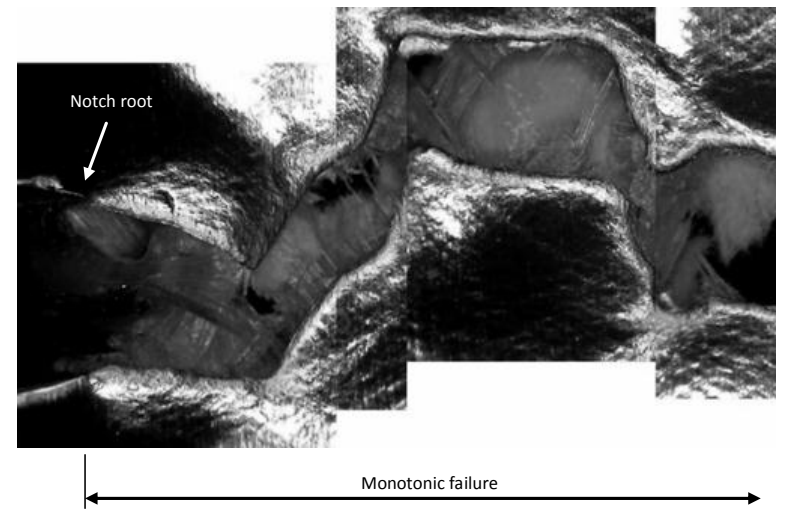

(b) $R=0.5,45 / 45$

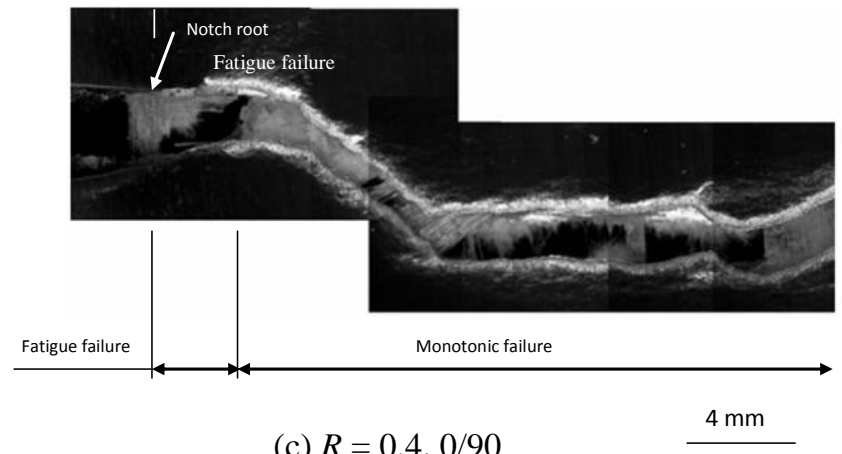

Figure 8 Examples of failure conditions

Besides the bridging, the lifetime of the FMLs in relation to crack growth is also affected by the stress in front of the crack tip among the layers composing the FMLs (Khan et al., 2011; Huang et al., 2015). The delamination will affect the crack growth rate. This is caused by the highstress concentration in the tiny zone in front of the crack tip and the differences in mechanical properties between the materials composing the FMLs. Consequently, the responses of each material in the zone to the stress concentration are not the same. This may mean that the displacement in the zone in front of the crack tip is also not the same, so delamination will begin and grow as the number of the cycles increases (Khan et al., 2011; Huang et al., 2015). Because of this, the stress distribution in front of the crack tip between the aluminium and fiberglass-epoxy composite in the FMLs was investigated.

Figure 9 shows an example of the contour of stress distribution obtained from the simulation in the vicinity of the crack tip in the case of the fiberglass orientated at $90^{\circ} / 0^{\circ}$ with $R=0.3$. The figure shows that there is a different stress distribution between the aluminium laminate and the fiberglass-epoxy composite laminate, especially in the vicinity of the crack tip, as indicated by the differences in the contour color of the stress. Because the crack growth in the FMLs occurred mostly on the aluminium laminate, as indicated by the bridging shown in Figure 8, the simulation was therefore carried out with the assumption based on this condition. For convenience, the results of the stress distribution are summarized in Figure 10, based on the magnitude of the stress in front of the crack near the tip for each crack length. 


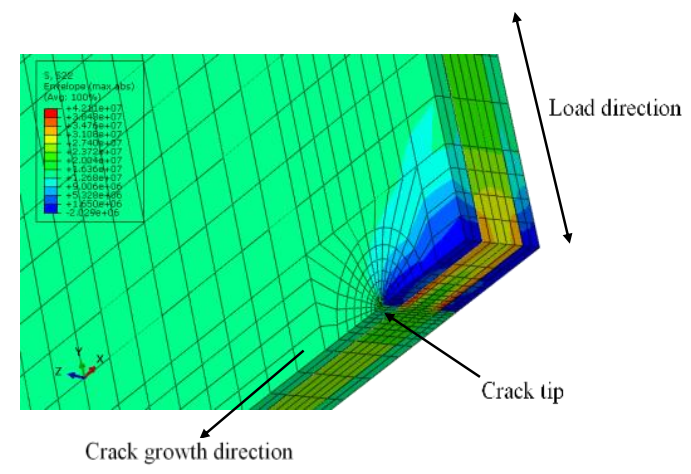

Figure 9 Contour example of normal stress distribution in the vicinity of the crack tip at the point of maximum cyclic load for fiberglass orientation $90 \% 0^{\circ}$ with $R=0.3$

With respect to Figue 10, it can be seen that the stress near the crack tip varies, depending on the crack length. In the case of the monolithic aluminium, it is usual that the stress increases as the crack length becomes longer, and it is also affected by the value of the stress ratio. Higher stress occurs at higher stress ratios, which consequently causes fatigue life to be shorter at these ratios. The stress in the aluminium layer of the FMLs is lower than that in the monolithic cases, whether in the interior (int.) or exterior (ext.) of the surface of the aluminium, as shown in Figure 10a, in which the orientation of the fiberglass is $90^{\circ} / 0^{\circ}$. Because of this, the fatigue life of the monolithic aluminium is shorter than that of the FMLs for each stress ratio. The stress of the FMLs with fiberglass orientation of $45^{\circ} / 45^{\circ}$ is also lower compared to what occurs in the monolithic aluminium, so the fatigue life of the FMLs with this fiberglass orientation is still higher than that which occurs in the monolithic aluminium for every stress ratio, as shown in Figure 10b. The stress on the exterior and interior surface of the aluminium of the FMLs near the crack tip for each crack length is different. The stress in the interior surface is that which occurs at the interface between the aluminium and fiberglass-epoxy composite. In Figures 10a and $10 \mathrm{~b}$, for FMLs with fiberglass orientations of $90^{\circ} / 0^{\circ}$ and $45^{\circ} / 45^{\circ}$, respectively, it is shown that the stress on the exterior is higher than what takes place on the interior surface for each stress ratio. The stress variation taking place on the exterior is shown only for stress ratios 0 and 0.5. This is simply for convenience in observing the figure; however, the tendency of the stress variation can be established. It is plausible that the lower stress variation in the interior, compared to the exterior, surface of the aluminium laminate causes the bridging during crack growth in the aluminium laminate. The reason why the FMLs with $45^{\circ} / 45^{\circ}$ fiberglass orientation have lower fatigue life than those with $90^{\circ} / 0^{\circ}$ is that the stress variation is higher in the former than in the latter, as indicated in Figure 10c. Although Figure 10c only shows the stress ratio of 0.4 , also for ease of observation, the same tendency occurs in the other load conditions. The stress variation in front of the crack tip for the $90^{\circ} / 0^{\circ}$ cases is lower than what occurs in the $45^{\circ} / 45^{\circ}$ ones. There is fiber orientation, which is parallel to the load direction in the $90^{\circ} / 0^{\circ}$ case. Hence, when the crack occurs, the stress distributed to the fiber is in the same direction as the fiber over the crack region behind the crack tip. This leads to the bridging stress being higher than that which takes place in the $45^{\circ} / 45^{\circ}$ case. The high bridging stress over the crack region lowers the stress intensity factor on the aluminium laminate (Khan et al., 2011; Huang et al., 2015), and reduces the stress concentrated in front of the crack tip. 


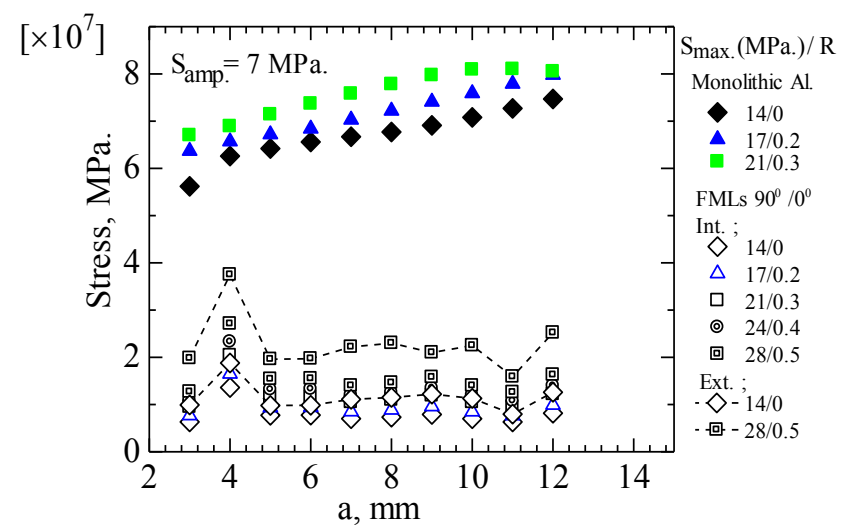

(a) $90 \% 0^{\circ}$ Fiber orientation

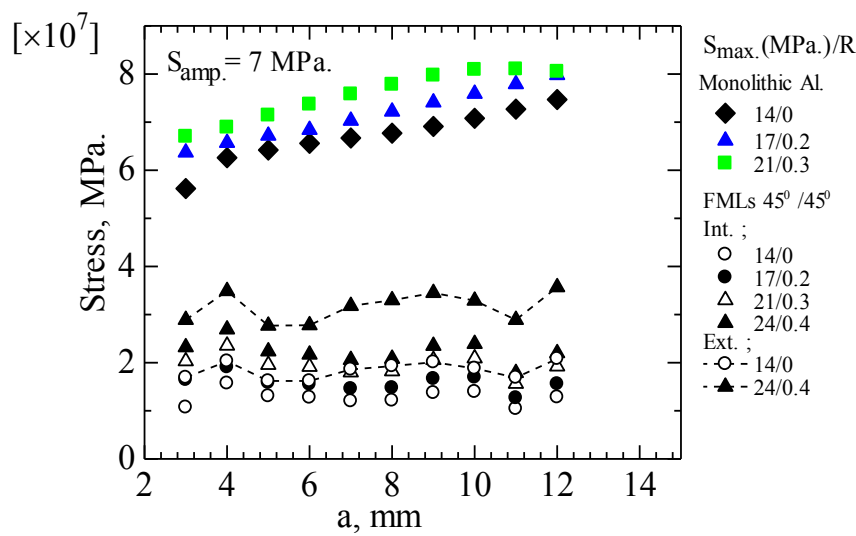

(b) $45^{\circ} / 45^{\circ}$ Fiber orientation

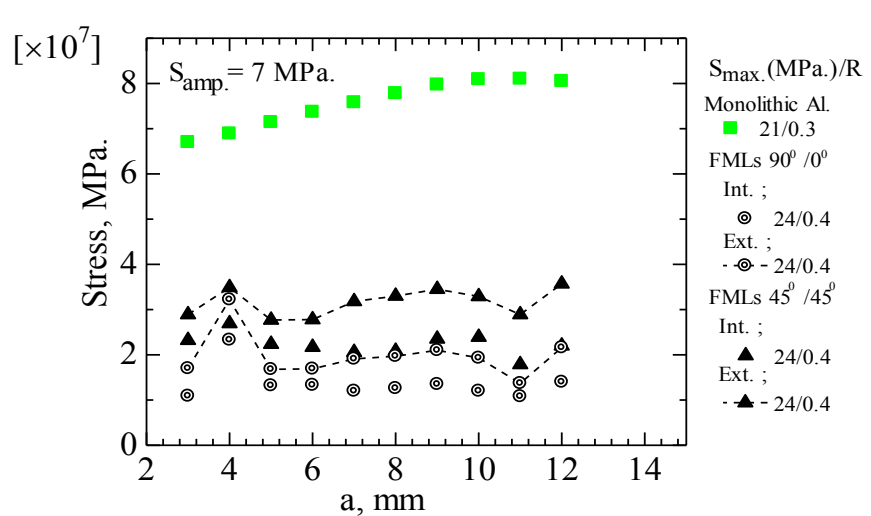

(c). Comparison between $90^{\circ} / 0^{\circ}$ and $45^{\circ} / 45^{\circ}$ fiberglass orientation

Figure 10 Stress variation in front of the crack tip for each crack length

\section{CONCLUSION}

The study shows that the crack growth behavior of FMLs under a cyclic constant load is influenced by the conditions of the load. It can be concluded that the crack growth behavior is affected by the stress ratio and the fiberglass orientation. A higher stress ratio causes the stress concentrating just in front of the crack tip also to be higher, which causes the fatigue life to decrease. Because this concentration in the FMLs with $45^{\circ} / 45^{\circ}$ fiberglass orientation is higher than that of the $90^{\circ} / 0^{\circ}$ cases, the fatigue life of the $45^{\circ} / 45^{\circ}$ FMLs is shorter. In addition, bridging of the fiber-epoxy composite takes place when the stress ratio of the constant cyclic load is lower than 0.4 , which also enhances the fatigue life. 


\section{REFERENCES}

Bao, H., McEvily, A.J., 1995. The Effect of Overload on the Rate of Crack Propagation under Plane Stress Conditions. Metallurgical and Materials A, Volume 26(7), pp. 1725-1733

Barsom, J.M., Rofle S.T., 1999. Fracture and Fatigue Control in Structure: Applications of Fracture. $3^{\text {rd }}$ edition, ASTM, Philadelphia, USA

Callister Jr., W.D., Rethwisch, D.G., 2007. Fundamental of Material Science and Engineering: An Integrated Approach. $3^{\text {rd }}$ edition, John Wiley \& Sons, New York, USA

Dadej, K., Bienias, J., Surowska, B., 2017. Residual Fatigue Life of Carbon Fibre Aluminium Laminates. International Journal of Fatigue, Volume 100, pp. 94-104

Huang, Y., Liu, J., Huang, X., Zhang, J., Yue, G., 2015. Delamination and Fatigue Crack Growth Behavior in Fiber Metal Laminates (Glare) under Single Overloads. International Journal of Fatigue, Volume 78(8), pp. 53-60

Jianyu, Z., Lei, P., Libin, Z., Binjun, F., 2012. Fatigue Delamination Growth Rates and Thresholds of Composite Laminates under Mixed Mode Loading. International Journal of Fatigue, Volume 40, pp. 7-15

Jones R., Kinloch A.J., Hu, W., 2016. Cyclic-fatigue Crack Growth in Composite and Adhesively-bonded Structures: The FAA Slow Crack Growth Approach to Certification and the Problem of Similitude. International Journal of Fatigue, Volume 88, pp. 10-18

Jones, R.M., 1999. Mechanics of Composite Materials. $2^{\text {nd }}$ edition, Taylor \& Francis Inc., Philadelphia, USA

Khan S.U., Alderliesten R.C., Benedictus R., 2011. Delamination in Fiber Metal Laminates (GLARE) during Fatigue Crack Growth under Variable Amplitude Loading. International Journal of Fatigue, Volume 33(9), pp. 1292-1303

Purnowidodo, A., Fukuzato, S., Saimoto, A., Makabe, C., 2007. Crack Growth Behavior in Overloaded Specimens with Sharp Notch in Low Carbon Steel. Journal of Testing Evaluation, Volume 35(5), pp. 463-468

Purnowidodo, A., Makabe, C., 2009. The Crack Growth Behavior after Overloading on Rotating Bending Fatigue. Engineering Failure Analysis, Volume 16(7), pp. 2245-2254

Purnowidodo, A., Makabe. C., Miyazaki, T., Mc.Evily, A.J., 2004. Transitional Behavior of Residual Fatigue Life after Applying Overload during Fatigue Crack Growth with Constant Stress Amplitude. In: Proceeding of Pressure vessel and piping codes and standards 2004, San Diego, USA, pp. 39-44

Purnowidodo, A., Soenoko, R., Choiron, M.A., 2016. The effect of Hold Time of Overload on Crack Propagation Behavior Emerging from Notch Root. FME Transactions, Volume 44(1), pp. 50-57

Sadananda, K., Vasudevan, A.K., Holtz, R.L., Lee E.U., 1999. Analysis of Overload Effects and Related Phenomena. International Journal of Fatigue, Volume 21(1S), pp. S233-S246

Stephens, R.I., Fatemi, A., Stephens, R.R., Fuchs, H.O., 2001. Metal Fatigue in Engineering. $2^{\text {nd }}$ edition, John Wiley \& Sons, New York, USA 